\title{
Quantitative Analysis of Swallowing Function Between Dysphagia Patients and Healthy Subjects Using High-Resolution Manometry
}

\author{
Chul-Hyun Park, $\mathrm{MD}^{1}$, Don-Kyu Kim, MD, PhD², Yong-Taek Lee, MD, PhD ${ }^{1}$, Youbin Yi, $\mathrm{MD}^{3}$,
} Jung-Sang Lee, $\mathrm{MD}^{1}$, Kunwoo Kim, $\mathrm{MD}^{1}$, Jung Ho Park, $\mathrm{MD}$, $\mathrm{PhD}^{4}$, Kyung Jae Yoon, MD, $\mathrm{PhD}^{1}$

\begin{abstract}
${ }^{1}$ Department of Physical and Rehabilitation Medicine, Kangbuk Samsung Hospital, Sungkyunkwan University School of Medicine, Seoul; ${ }^{2}$ Department of Physical and Rehabilitation Medicine, Chung-Ang University College of Medicine, Seoul; ${ }^{3}$ Department of Physical and Rehabilitation Medicine, Eulji University Hospital, Seoul; ${ }^{4}$ Division of Gastroenterology, Department of Internal Medicine, Kangbuk Samsung Hospital, Sungkyunkwan University School of Medicine, Seoul, Korea
\end{abstract}

\begin{abstract}
Objective To compare swallowing function between healthy subjects and patients with pharyngeal dysphagia using high resolution manometry (HRM) and to evaluate the usefulness of HRM for detecting pharyngeal dysphagia.

Methods Seventy-five patients with dysphagia and 28 healthy subjects were included in this study. Diagnosis of dysphagia was confirmed by a videofluoroscopy. HRM was performed to measure pressure and timing information at the velopharynx (VP), tongue base (TB), and upper esophageal sphincter (UES). HRM parameters were compared between dysphagia and healthy groups. Optimal threshold values of significant HRM parameters for dysphagia were determined.

Results VP maximal pressure, TB maximal pressure, UES relaxation duration, and UES resting pressure were lower in the dysphagia group than those in healthy group. UES minimal pressure was higher in dysphagia group than in the healthy group. Receiver operating characteristic (ROC) analyses were conducted to validate optimal threshold values for significant HRM parameters to identify patients with pharyngeal dysphagia. With maximal VP pressure at a threshold value of $144.0 \mathrm{mmHg}$, dysphagia was identified with $96.4 \%$ sensitivity and $74.7 \%$ specificity. With maximal TB pressure at a threshold value of $158.0 \mathrm{mmHg}$, dysphagia was identified with $96.4 \%$ sensitivity and $77.3 \%$ specificity. At a threshold value of $2.0 \mathrm{mmHg}$ for UES minimal pressure, dysphagia was diagnosed at $74.7 \%$ sensitivity and $60.7 \%$ specificity. Lastly, UES relaxation duration of $<0.58$ seconds had $85.7 \%$ sensitivity and $65.3 \%$ specificity, and UES resting pressure of $<75.0 \mathrm{mmHg}$ had $\mathbf{8 9 . 3 \%}$ sensitivity and $90.7 \%$ specificity for identifying dysphagia. Conclusion We present evidence that HRM could be a useful evaluation tool for detecting pharyngeal dysphagia.
\end{abstract}

Keywords Deglutition disorders, Manometry, Pharynx, Upper esophageal sphincter

Received January 4, 2017; Accepted March 27, 2017

Corresponding author: Kyung Jae Yoon

Department of Physical and Rehabilitation Medicine, Kangbuk Samsung Hospital, Sungkyunkwan University School of Medicine, 29 Saemunan-ro, Jongno-gu, Seoul 03181, Korea. Tel: +82-2-2001-1865, Fax: +82-2-2001-2176, E-mail: kint99@gmail.com

ORCID: Chul-Hyun Park (http://orcid.org/0000-0002-9897-6612); Don-Kyu Kim (http://orcid.org/0000-0001-8619-830X); Yong-Taek Lee (http://orcid. org/0000-0001-6611-0999); Youbin Yi (http://orcid.org/0000-0001-5707-3815); Jung-Sang Lee (http://orcid.org/0000-0001-5423-3772); Kunwoo Kim (http://orcid.org/0000-0002-4729-5243); Jung Ho Park (http://orcid.org/0000-0002-8367-4371); Kyung Jae Yoon (http://orcid.org/0000-0002-2765-4309).

(c) This is an open-access article distributed under the terms of the Creative Commons Attribution Non-Commercial License (http://creativecommons.org/ licenses/by-nc/4.0) which permits unrestricted noncommercial use, distribution, and reproduction in any medium, provided the original work is properly cited. Copyright (C) 2017 by Korean Academy of Rehabilitation Medicine 


\section{INTRODUCTION}

Swallowing is a complex neuromuscular event involving structures in the oral cavity, pharynx, and esophagus. Ineffective swallowing can lead to serious health problem that can affect the quality of life [1-3]. Therefore, accurate and meticulous evaluation of swallowing function using adequate diagnostic methods is necessary for diagnosis of swallowing disorders [4]. Videofluoroscopic swallow study (VFSS) is the standard method for the evaluation of swallowing function [5]. However, the limitations of VFSS relate to prolonged radiation exposure to patients and allergies to contrast materials [6,7]. In addition, VFSS is not portable, which limits its applications in bed-ridden patients [6]. Moreover, information obtained from VFSS consists mainly of qualitative visual-perceptual assessments, which are substantially dependent on examiners, even though a few quantitative measurements such as oral transit time, pharyngeal constriction ratio, and diameter of the upper esophageal sphincter (UES) are possible [8-11]. However, these quantitative measurements using VFSS are considered cumbersome and timeconsuming, and they cannot offer objective pressure and time information for the swallowing system $[8,11]$.

Manometry can be used to quantitatively estimate the swallowing process in a rapid and direct way without using radiation or contrast materials [12]. Moreover, it has a significant advantage as a portable device that requires minimal positioning of the patient. It can easily evaluate bed-ridden patients, even those in intensive care units [13]. Previously, conventional manometry had limitations to coverage along the entire pharynx and esophagus because only a few sensors were used. To solve this limitation, high resolution manometry (HRM) was developed to overcome the paucity of sensors by using 36 circumferential sensors located at $1 \mathrm{~cm}$ intervals on the catheter, and has been successfully used to calculate the generated pressure events along the swallowing system [14].

At present, esophageal HRM is used in the diagnosis of esophageal motility disorders [15]. However, only a few studies have used pharyngeal HRM for patients with pharyngeal dysphagia. Previous studies focused only on correlations between VFSS and HRM parameters, which are strong $[11,16,17]$. However, to apply pharyngeal HRM to dysphagia patients in a clinical setting, a comparison study between healthy subjects and dysphagia patients is needed to determine the usefulness of HRM for detecting pharyngeal dysphagia. To the best of our knowledge, no previous studies have established threshold values for HRM parameters to determine the presence of pharyngeal dysphagia with sensitivities, specificities, and predictive values.

Therefore, the objectives of this study were: (1) to compare swallowing functions between dysphagia patients and healthy subjects by using HRM and (2) to establish optimal threshold values for HRM parameters and determine their sensitivities, specificities, and predictive values for identifying pharyngeal dysphagia.

\section{MATERIALS AND METHODS}

\section{Study subjects}

Seventy-five patients with pharyngeal dysphagia who were followed in our rehabilitation unit and 28 healthy subjects were included in the present study. Inclusion criteria were: (1) any clinical symptom of dysphagia such as globus sensation, choking, coughing after swallowing, or sensing food stuck in throat, (2) confirmed diagnosis of dysphagia by VFSS evaluation, and (3) VFSS followed by HRM within 2 days. Patients were excluded if they had severe psychiatric impairment or poor cooperation for performing both VFSS and HRM. The diagnosis of pharyngeal dysphagia was based on VFSS findings which demonstrated any one of the following abnormalities: pharyngeal stage retention, airway penetration, and aspiration [18-20]. Pharyngeal stage retention was demonstrated with the presence of bolus remnants (mild, moderate, or severe) in valleculae or pyriform sinuses after initial swallowing. Subsequently, re-swallowing was conducted to confirm the ability of patient to clear the pharyngeal remnants to determine the severity of dysphagia $[18,19]$. Airway penetration was defined as bolus material that passes into the laryngeal vestibule without entering below the level of vocal cords. Aspiration was defined as bolus material entering through the level of the vocal cords [20]. The functional status of study subjects was described as patients being able to walk without assistance or to talk and obey a three-step command. The current feeding status of study subjects was documented as normal oral feeding, modified oral feeding, or nasogastric tube feeding based on VFSS findings. Modified oral feeding was recommended to patients having safe oral swal- 
lowing function only when diet consistency was modified. Nasogastric tube feeding was recommended when oral feeding was deemed inappropriate because of high risk of aspiration $[19,20]$. Moreover, the dysphagia severity of study subjects was determined using a validated scale, the Dysphagia Outcome and Severity Scale (DOSS), based on the findings of VFSS, such as pharyngeal stage retention, penetration, and airway aspiration. DOSS is a 7-level scale with high intra-rater (93\%) and inter-rater
(90\%) reliabilities, and is widely used to systemically rate the dysphagia severity of study subjects [18]. Severity levels of DOSS are 1 (severe dysphagia), 2 (moderately severe dysphagia), 3 (moderate dysphagia), 4 (mild to moderate dysphagia), 5 (mild dysphagia), 6 (functional limitation), and 7 (within normal limits) (Table 1).

All healthy subjects had no histories of swallowing difficulty, neurological disorders, or any known medical conditions. Furthermore, the healthy group was confirmed

Table 1. Basic characteristics in the dysphagia and healthy groups

\begin{tabular}{|c|c|c|c|}
\hline Variable & $\begin{array}{c}\text { Dysphagia group } \\
(n=75)\end{array}$ & $\begin{array}{c}\text { Healthy group } \\
(\mathbf{n}=28)\end{array}$ & p-value \\
\hline Age (yr) & $62.5 \pm 12.1$ & $44.6 \pm 18.3$ & $<0.01^{*}$ \\
\hline Gender & & & 0.105 \\
\hline Male & 52 & 14 & \\
\hline Female & 23 & 14 & \\
\hline Height $(\mathrm{cm})$ & $165.6 \pm 7.2$ & $165.6 \pm 8.6$ & 0.962 \\
\hline Weight (kg) & $60.7 \pm 10.2$ & $62.1 \pm 10.3$ & 0.552 \\
\hline Able to walk without assistance (\%) & 49.3 & 100 & $<0.01^{*}$ \\
\hline Able to talk and obey 3 -step command (\%) & 56.0 & 100 & $<0.01^{*}$ \\
\hline \multicolumn{4}{|l|}{ Feeding status } \\
\hline Normal oral feeding & - & 28 & - \\
\hline Modified oral feeding & 43 & - & - \\
\hline Nasogastric tube feeding & 32 & - & - \\
\hline Dysphagia Outcome and Severity Scale & $3.3 \pm 1.3$ & 7.0 & $<0.01^{*}$ \\
\hline Level 1 (severe dysphagia) & 3 & - & - \\
\hline Level 2 (moderately severe dysphagia) & 29 & - & - \\
\hline Level 3 (moderate dysphagia) & 9 & - & - \\
\hline Level 4 (mild to moderate dysphagia) & 13 & - & - \\
\hline Level 5 (mild dysphagia) & 20 & - & - \\
\hline Level 6 (functional limitation) & 1 & - & - \\
\hline Level 7 (normal in all situations) & - & 28 & - \\
\hline \multicolumn{4}{|l|}{ Underlying etiologies of dysphagia } \\
\hline Stroke & 40 & & \\
\hline Head and neck cancer & 8 & & \\
\hline Unknown & 7 & & \\
\hline Dementia & 6 & & \\
\hline Cervical spine operation & 5 & & \\
\hline Vocal cord palsy & 3 & & \\
\hline Traumatic brain injury & 2 & & \\
\hline Parkinson disease & 2 & & \\
\hline Guillain-Barre syndrome & 1 & & \\
\hline Multiple sclerosis & 1 & & \\
\hline
\end{tabular}

Values are presented as mean \pm standard deviation or number.

*Significant differences between the two groups $(\mathrm{p}<0.01)$. 
based on normal findings of VFSS (Table 1). Study subjects who were willing to participate in this study were informed about the purpose of the study and the details of the study process. Informed consent was obtained from every participant who was included in the study. The study protocol was approved by the Institutional Review Board (2014-08-005) of Sungkyunkwan University.

\section{HRM procedure}

We used a solid-state high-resolution manometric assembly (outer diameter of $4.2 \mathrm{~mm}$ ) with 36 circumferential sensors spaced at $1-\mathrm{cm}$ intervals (Given Imaging Los Angeles, Inglewood, CA, USA) [21]. Before HRM evaluation, transducers were calibrated at 0 and $350 \mathrm{mmHg}$ using externally applied pressure. The HRM procedure was performed the subjects in an upright sitting position after 8 hours of fasting. The HRM catheter was positioned to record from the velopharynx (VP) to UES. The HRM catheter was then fixed to the nose with tape. The parameters of HRM were assessed for five swallows with $5 \mathrm{~mL}$ water to reduce the observer error, and the mean of the five values for HRM parameters were estimated.

For HRM data analysis, ManoView analysis software (Sierra Scientific Instruments, Los Angeles, CA, USA) was used based on previously established methods [14,21]. Manometrically defined regions of interests (ROI) were as follows: VP, tongue base (TB), and UES (Fig. 1). VP was defined as the area of swallow-related pressure change proximal to the area of continuous nasal nostril quiescence, extending $2 \mathrm{~cm}$ caudally. Anatomically, VP comprised the soft palate (also called velum) and posterior

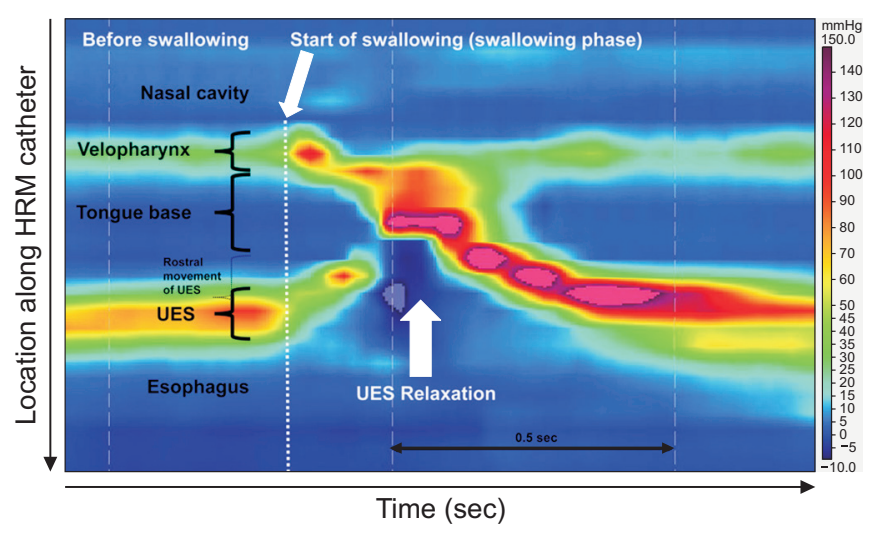

Fig. 1. Regions of interest for high-resolution manometry (HRM) procedure. UES, upper esophageal sphincter. pharynx. TB was defined as the area of swallow-related pressure change, with a high-pressure area midway between VP and UES. The TB mid-point was the maximal pressure point and it extended $2 \mathrm{~cm}$ above and below that point. The UES region was defined as the epicenter of stable high pressure beginning just proximal to the baseline low esophageal pressure zone, and extending to a point of low esophageal pressure distal and low baseline pharyngeal pressure proximal. UES is composed of cricopharyngeal and inferior pharyngeal muscles. This anatomical area is mobile along the catheter during swallowing phase, moving rostral as much as $2-4 \mathrm{~cm}$ (Fig. 1). Several parameters, including VP maximal pressure, VP duration, TB maximal pressure, TB duration, UES maximal pressure, UES minimal pressure, UES relaxation duration, and UES resting pressure were recorded. Means and standard deviations (SD) of each HRM parameter were estimated. Duration of pressure above baseline within ROI was defined as the interval between the onset and offset of pressure increase on the relevant sensor. UES relaxation duration was defined as the interval from the onset, at the point of departure from half the baseline pressure, to the offset at the return to half-baseline pressure $[22,23]$. UES minimal pressure was the minimum UES pressure during UES relaxation in swallowing phase. UES resting pressure was defined as the maximal pressure occurring during normal respiratory cycle (nonswallowing phase) $[14,21,24,25]$.

\section{Statistical analysis}

Data are presented as mean \pm SD. Categorical data of study subjects were compared by chi-square analysis. Comparison of means between the dysphagic and healthy groups was performed using Student t-test. Additionally, comparisons of age-adjusted means between the two groups were analyzed using analysis of covariance (ANCOVA). Additionally, correlations between the significant HRM parameters and DOSS were assessed by Pearson correlation coefficient (r).

The validity of significant HRM parameters for identifying pharyngeal dysphagia in comparison with healthy swallowing was evaluated by receiver operating characteristic (ROC) curve analysis. Optimal threshold levels with maximum sensitivity and specificity were determined. The level of statistical significance was set at $\mathrm{p}<0.05$. 
All data analyses were performed using Statistical Package for the Social Sciences (SPSS) ver. 18.0 (SPSS Inc., Chicago, IL, USA).

\section{RESULTS}

Comparisons between the dysphagia and healthy groups

Basic characteristics of the study subjects and the underlying etiologies of dysphagia are summarized in Table

Table 2. Comparison of HRM parameters between dysphagia and healthy groups

\begin{tabular}{|lcccc}
\hline Variable & $\begin{array}{c}\text { Dysphagia group } \\
(\mathbf{n = 7 5 )}\end{array}$ & $\begin{array}{c}\text { Healthy group } \\
(\mathbf{n = 2 8})\end{array}$ & p-value & $\begin{array}{c}\text { Adjusted } \\
\text { p-value }\end{array}$ \\
\hline HRM parameters & & & & \\
VP maximal pressure (mmHg) & $116.60 \pm 39.28$ & $221.55 \pm 61.03$ & $<0.01$ & $<0.01^{*}$ \\
\hline VP duration (s) & $0.66 \pm 0.22$ & $0.64 \pm 0.14$ & 0.619 & 0.303 \\
\hline TB maximal pressure (mmHg) & $137.66 \pm 72.76$ & $214.56 \pm 53.81$ & $<0.01$ & $<0.01^{*}$ \\
\hline TB duration (s) & $0.58 \pm 0.09$ & $0.57 \pm 0.12$ & 0.469 & 0.545 \\
\hline UES maximal pressure (mmHg) & $260.43 \pm 71.94$ & $279.55 \pm 49.02$ & 0.198 & 0.251 \\
\hline UES minimal pressure (mmHg) & $6.42 \pm 8.13$ & $0.69 \pm 5.54$ & $<0.01$ & $0.019^{*}$ \\
\hline UES relaxation duration (s) & $0.49 \pm 0.19$ & $0.68 \pm 0.12$ & $<0.01$ & $<0.01^{*}$ \\
\hline UES resting pressure (mmHg) & $44.23 \pm 34.97$ & $96.27 \pm 20.31$ & $<0.01$ & $<0.01^{*}$ \\
\hline
\end{tabular}

Values are presented as mean \pm standard deviation.

HRM, high-resolution manometry; VP, velopharynx; TB, tongue base; UES, upper esophageal sphincter.

*Significant differences between the two groups using ANCOVA (age-adjusted $\mathrm{p}<0.05$ ).
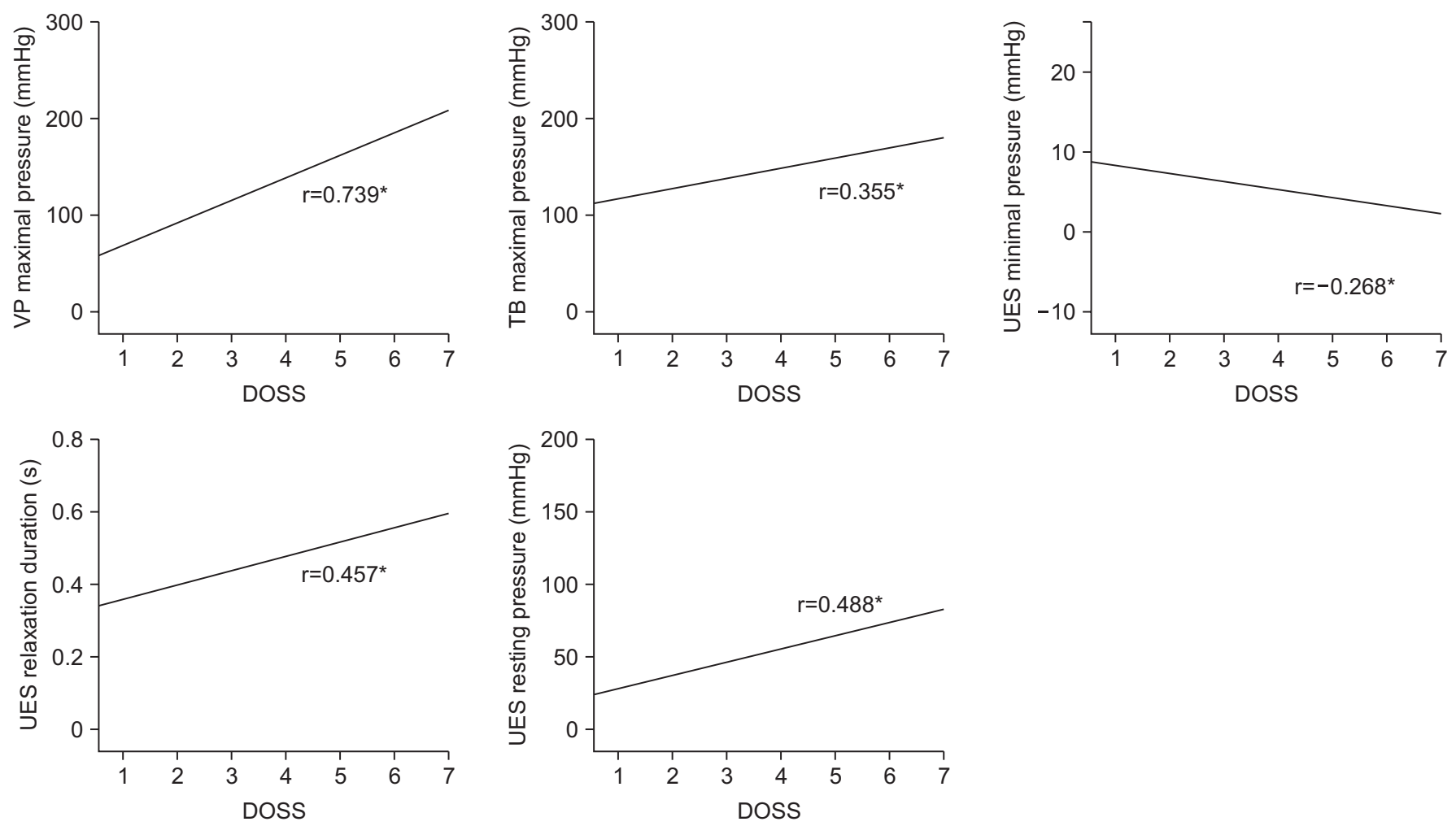

Fig. 2. Relationship between Dysphagia Outcome and Severity Scale (DOSS) and significant HRM parameters in study subjects. The p-values were analyzed by Pearson correlation coefficient (r). Asterisk indicates p-value of less than 0.01 . HRM, high-resolution manometry; VP, velopharynx; TB, tongue base; UES, upper esophageal sphincter. 
1. The dysphagia group was significantly older than the healthy group ( $62.5 \pm 12.1$ vs. $44.6 \pm 18.3$ years; $\mathrm{p}<0.01)$.

VP maximal pressure, TB maximal pressure, UES relaxation duration, and UES resting pressure were lower for the dysphagia group than for the healthy group (ageadjusted $\mathrm{p}<0.01)$. UES minimal pressure was higher in the dysphagia group than that in the healthy group (ageadjusted $\mathrm{p}=0.019$ ) (Table 2). Significant HRM parameters, including VP maximal pressure, TB maximal pressure, UES relaxation duration, and UES resting pressure were positively correlated with DOSS; UES minimal pressure was negatively correlated with DOSS (Fig. 2).

\section{Optimal threshold values of significant HRM parameters for identifying dysphagia}

ROC analyses were carried out to reveal the optimal threshold values for significant HRM parameters to identify dysphagia with reasonable sensitivities, specificities, and predictive values (Table 3, Fig. 3). For VP maximal pressure at an optimal threshold value of 144.0 $\mathrm{mmHg}$, dysphagia was identified with a sensitivity of $96.4 \%$ and a specificity of $74.7 \%$ (area under the ROC curve $[\mathrm{AUC}]=0.938, \mathrm{p}<0.01)$. For TB maximal pressure at a threshold of $158.0 \mathrm{mmHg}$, dysphagia was identified with a sensitivity of $96.4 \%$ and a specificity of $77.3 \%$ (AUC $=0.866, \mathrm{p}<0.01$ ).

At an optimal threshold value of $2.0 \mathrm{mmHg}$ for UES minimal pressure, patients with dysphagia were identified with $74.7 \%$ sensitivity and $60.7 \%$ specificity
(AUC=0.714, $\mathrm{p}<0.01$ ). For UES relaxation duration of 0.58 sec, dysphagia was identified with $85.7 \%$ sensitivity and $65.3 \%$ specificity (AUC $=0.819, \mathrm{p}<0.01$ ). UES resting pressure at a threshold value of $75.0 \mathrm{mmHg}$ had a sensitivity of $89.3 \%$ and a specificity of $90.7 \%$ for identifying patients with pharyngeal dysphagia (AUC=0.933, $\mathrm{p}<0.01$ ).

\section{DISCUSSION}

The present study used HRM to compare swallowing function between dysphagia patients and healthy subjects, and found significant HRM parameters related to pharyngeal dysphagia. Furthermore, we demonstrated the optimal threshold values of these significant HRM parameters for identifying pharyngeal dysphagia with reasonable sensitivities, specificities, and predictive values.

The maximal pressure of VP turned out to be a significant HRM parameter associated with pharyngeal dysphagia. In contrast, the duration of VP using HRM lacked significance (Table 2). This result is in line with a previous study demonstrating that VP maximal pressure is correlated with the presence of subglottic aspiration seen on VFSS [16]. Moreover, our finding that TB maximal pressure is a significant parameter for determining pharyngeal dysphagia is consistent with the results obtained by Knigge and Thibeault [17], who demonstrated that decreased TB maximal pressure was associated with incomplete TB retraction seen on VFSS during swallowing

Table 3. Sensitivity, specificity and predictive values of the significant HRM parameters for identifying pharyngeal dysphagia

\begin{tabular}{lccccccc}
\hline $\begin{array}{c}\text { Significant HRM } \\
\text { parameters }\end{array}$ & $\begin{array}{c}\text { Optimal } \\
\text { threshold } \\
\text { level }\end{array}$ & $\begin{array}{c}\text { ROC area } \\
\text { under the } \\
\text { curve (95\% CI) }\end{array}$ & $\begin{array}{c}\text { Sensitivity (\%) } \\
(\mathbf{9 5 \%} \text { CI) }\end{array}$ & $\begin{array}{c}\text { Specificity (\%) } \\
(\mathbf{9 5 \%} \text { CI) }\end{array}$ & $\begin{array}{c}\text { PPV (\%) } \\
(\mathbf{9 5 \%} \text { CI) }\end{array}$ & $\begin{array}{c}\text { NPV (\%) } \\
(\mathbf{9 5 \%} \text { CI) }\end{array}$ \\
\hline VP maximal pressure (mmHg) & 144.0 & 0.938 & 96.4 & 74.7 & 58.7 & 98.2 \\
& & $(0.893-0.982)$ & $(81.7-99.9)$ & $(63.3-84.0)$ & $(43.2-73.0)$ & $(90.6-99.9)$ \\
TB maximal pressure (mmHg) & 158.0 & 0.866 & 96.4 & 77.3 & 61.4 & 98.3 \\
& & $(0.797-0.935)$ & $(81.7-99.9)$ & $(66.2-86.2)$ & $(45.5-75.6)$ & $(90.9-99.9)$ \\
UES minimal pressure (mmHg) & 2.0 & 0.714 & 74.7 & 60.7 & 83.6 & 47.2 \\
& & $(0.605-0.822)$ & $(63.3-84.0)$ & $(40.6-78.5)$ & $(72.5-91.5)$ & $(30.4-64.5)$ \\
UES relaxation duration (s) & 0.58 & 0.819 & 85.7 & 65.3 & 48.0 & 92.5 \\
& & $(0.737-0.901)$ & $(67.3-96.0)$ & $(53.5-76.0)$ & $(33.7-62.6)$ & $(81.8-97.9)$ \\
UES resting pressure (mmHg) & 75.0 & 0.933 & 89.3 & 90.7 & 78.1 & 95.8 \\
& & $(0.884-0.983)$ & $(71.8-97.7)$ & $(81.7-96.2)$ & $(60.0-90.7)$ & $(88.1-99.1)$ \\
\hline
\end{tabular}

HRM, high-resolution manometry; ROC, receiver operating curve; CI, confidence interval; PPV, positive predictive value; NPV, negative predictive value; VP, velopharynx; TB, tongue base; UES, upper esophageal sphincter. 

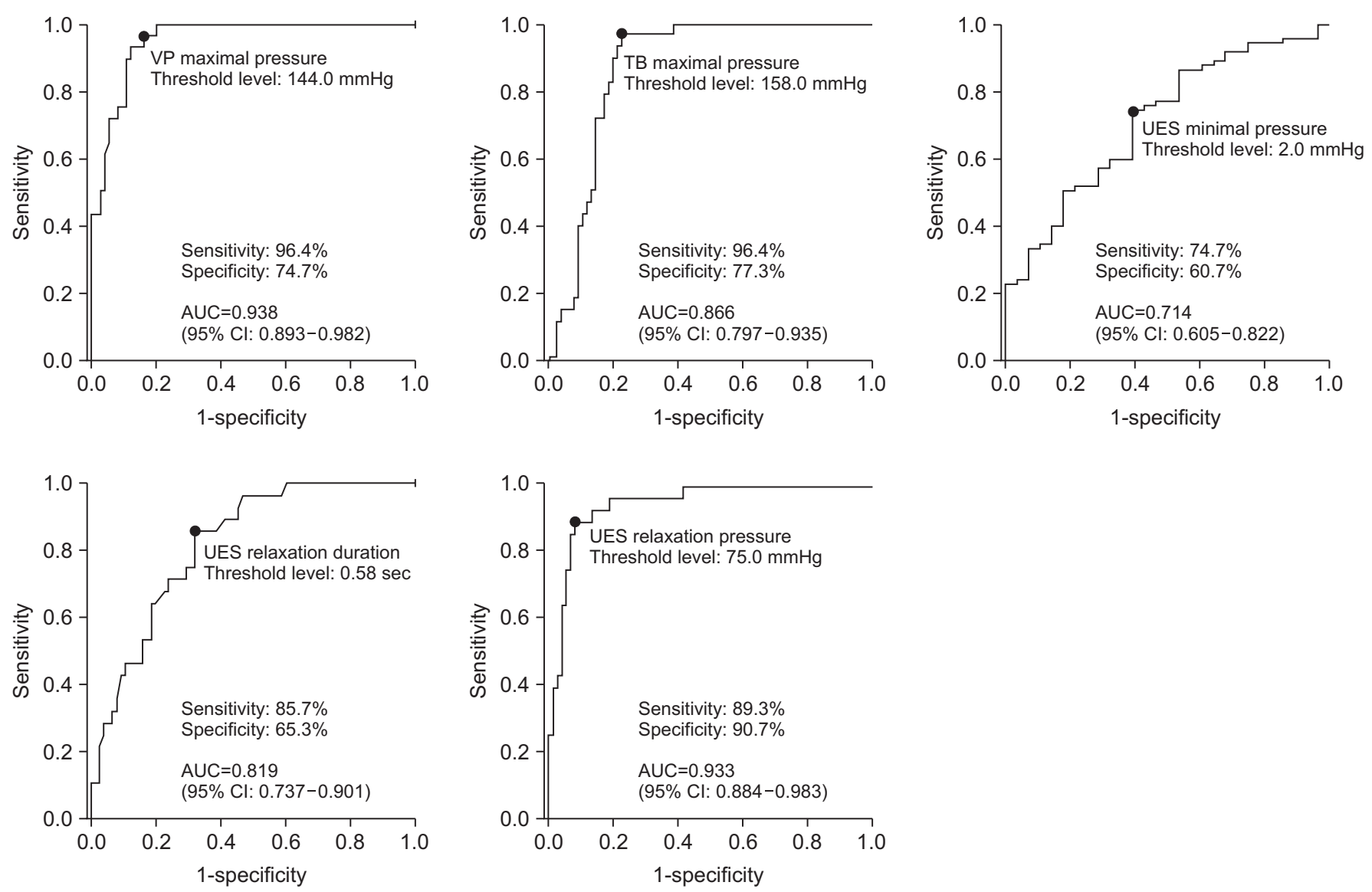

Fig. 3. The optimal threshold values of significant HRM parameters for identifying dysphagia on ROC analyses. HRM, high-resolution manometry; ROC, receiver operating curve; VP, velopharynx; TB, tongue base; UES, upper esophageal sphincter; PPV, positive predictive value; NPV, negative predictive value; CI, confidence interval.

in patients with dysphagia. One of main mechanisms of pharyngeal dysphagia is insufficient pharyngeal contraction and clearing force for bolus transmission through the pharynx [26]. VP and TB, as pressure-generating structures, move pharyngeal contents toward the UES by compressing between the soft palate, tongue and posterior pharyngeal wall during the pharyngeal contractile phase $[27,28]$. Therefore, measurements of VP and TB maximal pressure using HRM are important in identifying dysphagia patients with pharyngeal dysfunction.

In the assessment of UES using HRM, our study demonstrated that minimal pressure, relaxation duration, and resting pressure of UES were significant parameters for identification of pharyngeal dysphagia. However, UES maximal pressure was not a significant parameter for identifying dysphagia. An explanation for this finding is that the main function of UES during swallowing is related to decreasing resistance (relaxation), to allow bolus transmission through the UES, rather than generating contractile force $[29,30]$. Thus, instead of UES maximal pressure, the values of UES minimal pressure and UES relaxation duration can represent the opening and relaxation of UES while swallowing. These findings of the present study are consistent with the results of previous studies showing that UES minimal pressure and UES relaxation duration are associated with pharyngeal residues observed in VFSS [16]. Additionally, UES resting pressure emerged as a significant parameter for determining pharyngeal dysphagia in our study. To the best of our knowledge, this is a novel finding, demonstrating the significance of measuring UES resting pressure during the respiratory (non-swallowing) phase, because previous studies have performed HRM only in the course of the swallowing phase $[11,14,16,17,21]$. There are several advantages if we can evaluate dysphagia patients without performing bolus swallowing. First, measuring UES 
resting pressure of HRM during the respiratory (nonswallowing) phase can be performed for unconscious or bed-ridden patients, whereas VFSS requires adequate cognition to follow verbal orders in an upright sitting position. Second, UES resting pressure of HRM can be obtained without the risk of aspiration, while swallowing barium-coated material in VFSS is always accompanied with a risk of aspiration. Furthermore, in the context of diagnostic value of HRM for identifying dysphagia, we found that UES resting pressure had reasonable sensitivity, specificity, and predictive values among HRM parameters for the identification of patients with pharyngeal dysphagia.

Although some studies have used HRM in healthy people to evaluate the effect of compensatory swallowing maneuvers, few studies have been conducted using HRM for patients with pharyngeal dysphagia $[21,31,32]$. Moreover, previous studies only demonstrated the relationships between HRM and VFSS parameters in dysphagia patients or conducted HRM as a follow-up tool for dysphagia patients, without a healthy control group for comparison $[10,11,16,21]$. To the best of our knowledge, this study is the first to report threshold values of HRM parameters for identifying patients with pharyngeal dysphagia by comparison with HRM results of healthy controls. Therefore, the threshold values of significant HRM parameters established in this study could be used to aid clinical practice for diagnosing patients with pharyngeal dysphagia. Although HRM has limitations in visualizing bolus transmission along the pharynx and UES, HRM offers quantitative information on the pressure and timing values of swallowing structure in a rapid and objective way [21]. Moreover, HRM can be performed for barium allergic patients without radiation exposure at any place, including intensive care unit due to the portable feature of HRM.

The present study has several limitations. First, our study was conducted with dysphagia patients from only one hospital. Therefore, it is difficult to generalize our findings. More comprehensive data could be generated with a larger study through cooperation with other medical institutions. Second, the healthy and dysphagia groups of this study were not matched for age, and there was a significant difference in ages between the dysphagia group and the healthy group. However, to overcome this limitation, the results of HRM parameters were com- pared after adjusting for age to minimize this possible confounding effect, thus supporting the significance of our findings. Furthermore, Nishikubo et al. [33] reported that there was no significant difference in maximal pressure of VP, TB, or UES between healthy young and elderly subjects. However, decreased UES relaxation duration and insufficient reduction of UES minimal pressure were shown in the elderly group [33]. Although we have compared HRM parameters that are adjusted for age to minimize the confounding effect, parameters related to UES opening including UES relaxation duration and UES minimal pressure should be further investigated with age-matched controls in future large-scaled study. In addition, although HRM can be performed in both supine and sitting positions, HRM was conducted only in an upright sitting position in the present study. Zhang et al. [34] reported that there was no difference in UES basal pressure between sitting and supine position measured using HRM. However, to our knowledge, there has been no previous study that evaluated the effect of posture on VP and TB pressure using HRM. Thus, the influence of positional change on HRM parameters, including VP pressure and TB pressure, should be investigated in the future. Lastly, HRM needs to be performed after 8-hour fasting to prevent pharyngeal regurgitations and aspiration of gastric contents. This presents an inconvenience to patients in comparison with VFSS $[21,35]$. Therefore, clinicians should be aware of the limitations before performing HRM evaluation.

In conclusion, we present the usefulness of HRM for identifying pharyngeal dysphagia. Furthermore, we report optimal threshold values for significant HRM parameters. These results provide valuable information for detecting patients with pharyngeal dysphagia.

\section{CONFLICT OF INTEREST}

No potential conflict of interest relevant to this article was reported.

\section{ACKNOWLEDGMENTS}

The authors thank Ms. Miyeon Lee of Medical Information Library at Kangbuk Samsung Hospital for her advice about statistical analyses performed in the present study. 


\section{REFERENCES}

1. Daniels SK, Brailey K, Priestly DH, Herrington LR, Weisberg LA, Foundas AL. Aspiration in patients with acute stroke. Arch Phys Med Rehabil 1998;79:14-9.

2. Barer DH. The natural history and functional consequences of dysphagia after hemispheric stroke. J Neurol Neurosurg Psychiatry 1989;52:236-41.

3. Castell DO, Donner MW. Evaluation of dysphagia: a careful history is crucial. Dysphagia 1987;2:65-71.

4. Logemann JA. Approaches to management of disordered swallowing. Baillieres Clin Gastroenterol 1991;5:269-80.

5. Sorin R, Somers S, Austin W, Bester S. The influence of videofluoroscopy on the management of the dysphagic patient. Dysphagia 1988;2:127-35.

6. Gomes GF, Campos AC, Pisani JC, Macedo ED, Vieira MC. Diagnostic methods for the detection of anterograde aspiration in enterally fed patients. Curr Opin Clin Nutr Metab Care 2004;7:285-92.

7. Wright RE, Boyd CS, Workman A. Radiation doses to patients during pharyngeal videofluoroscopy. Dysphagia 1998;13:113-5.

8. Baijens L, Barikroo A, Pilz W. Intrarater and interrater reliability for measurements in videofluoroscopy of swallowing. Eur J Radiol 2013;82:1683-95.

9. Leonard R, Rees CJ, Belafsky P, Allen J. Fluoroscopic surrogate for pharyngeal strength: the pharyngeal constriction ratio (PCR). Dysphagia 2011;26:13-7.

10. Lan Y, Xu G, Dou Z, Wan G, Yu F, Lin T. Biomechanical changes in the pharynx and upper esophageal sphincter after modified balloon dilatation in brainstem stroke patients with dysphagia. Neurogastroenterol Motil 2013;25:e821-9.

11. Lan Y, Xu G, Dou Z, Lin T, Yu F, Jiang L. The correlation between manometric and videofluoroscopic measurements of the swallowing function in brainstem stroke patients with Dysphagia. J Clin Gastroenterol 2015;49:24-30.

12. Brasseur JG, Dodds WJ. Interpretation of intraluminal manometric measurements in terms of swallowing mechanics. Dysphagia 1991;6:100-19.

13. Cook IJ, Dodds WJ, Dantas RO, Kern MK, Massey BT, Shaker R, et al. Timing of videofluoroscopic, manometric events, and bolus transit during the oral and pharyngeal phases of swallowing. Dysphagia 1989;4:8-
15.

14. Takasaki K, Umeki H, Enatsu K, Tanaka F, Sakihama N, Kumagami $\mathrm{H}$, et al. Investigation of pharyngeal swallowing function using high-resolution manometry. Laryngoscope 2008;118:1729-32.

15. Roman S, Pandolfino J, Mion F. High-resolution manometry: a new gold standard to diagnose esophageal dysmotility? Gastroenterol Clin Biol 2009;33:1061-7.

16. Park D, Oh Y, Ryu JS. Findings of abnormal videofluoroscopic swallowing study identified by high-resolution manometry parameters. Arch Phys Med Rehabil 2016;97:421-8.

17. Knigge MA, Thibeault S. Relationship between tongue base region pressures and vallecular clearance. Dysphagia 2016;31:391-7.

18. O'Neil KH, Purdy M, Falk J, Gallo L. The dysphagia outcome and severity scale. Dysphagia 1999;14:13945.

19. Cherney LR, Cantieri CA, Pannell JJ. RIC clinical evaluation of dysphagia (CED). Rockville: Aspen Publishers; 1986. p. 41-2.

20. Rosenbek JC, Robbins JA, Roecker EB, Coyle JL, Wood JL. A penetration-aspiration scale. Dysphagia 1996;11:93-8.

21. McCulloch TM, Hoffman MR, Ciucci MR. High-resolution manometry of pharyngeal swallow pressure events associated with head turn and chin tuck. Ann Otol Rhinol Laryngol 2010;119:369-76.

22. Yoon KJ, Park JH, Park JH, Jung IS. Videofluoroscopic and manometric evaluation of pharyngeal and upper esophageal sphincter function during swallowing. J Neurogastroenterol Motil 2014;20:352-61.

23. Castell JA, Castell DO. Modern solid state computerized manometry of the pharyngoesophageal segment. Dysphagia 1993;8:270-5.

24. Omari TI, Miki K, Davidson G, Fraser R, Haslam R, Goldsworthy $\mathrm{W}$, et al. Characterisation of relaxation of the lower oesophageal sphincter in healthy premature infants. Gut 1997;40:370-5.

25. Kahrilas PJ, Dodds WJ, Dent J, Logemann JA, Shaker R. Upper esophageal sphincter function during deglutition. Gastroenterology 1988;95:52-62.

26. Cecconi E, Di Piero V. Dysphagia: pathophysiology, diagnosis and treatment. Front Neurol Neurosci 2012;30:86-9.

27. Matsuo K, Palmer JB. Anatomy and physiology of 
feeding and swallowing: normal and abnormal. Phys Med Rehabil Clin N Am 2008;19:691-707, vii.

28. Raol N, Hartnick CJ. Anatomy and physiology of velopharyngeal closure and insufficiency. Adv Otorhinolaryngol 2015;76:1-6.

29. Cook IJ, Dodds WJ, Dantas RO, Massey B, Kern MK, Lang IM, et al. Opening mechanisms of the human upper esophageal sphincter. Am J Physiol 1989;257(5 Pt 1):G748-59.

30. Sivarao DV, Goyal RK. Functional anatomy and physiology of the upper esophageal sphincter. Am J Med 2000;108 Suppl 4a:27S-37S.

31. Takasaki K, Umeki H, Hara M, Kumagami H, Takahashi $\mathrm{H}$. Influence of effortful swallow on pharyngeal pressure: evaluation using a high-resolution manometry. Otolaryngol Head Neck Surg 2011;144:16-20.

32. Umeki H, Takasaki K, Enatsu K, Tanaka F, Kumagami
$\mathrm{H}$, Takahashi H. Effects of a tongue-holding maneuver during swallowing evaluated by high-resolution manometry. Otolaryngol Head Neck Surg 2009;141:11922.

33. Nishikubo K, Mise K, Ameya M, Hirose K, Kobayashi T, Hyodo M. Quantitative evaluation of age-related alteration of swallowing function: videofluoroscopic and manometric studies. Auris Nasus Larynx 2015;42:1348.

34.Zhang XJ, Xiang XL, Tu L, Xie XP, Hou XH. The effect of position on esophageal structure and function determined with solid-state high-resolution manometry. J Dig Dis 2015;16:350-6.

35. Pandolfino JE, Kahrilas PJ; American Gastroenterological Association. AGA technical review on the clinical use of esophageal manometry. Gastroenterology 2005;128:209-24. 